\title{
Therapeutic Potential of Inhibiting Leukocyte Rolling in Ischemia/Reperfusion
}

\author{
Paul Kubes, * Mark Jutila, ${ }^{\ddagger}$ and Derrice Payne* \\ * Department of Medical Physiology, University of Calgary, Calgary, Alberta, T2N 4N1 Canada; and ${ }^{\ddagger}$ Veterinary Molecular Biology \\ Laboratory, College of Agriculture, Montana State University, Bozeman, Montana 59717
}

\begin{abstract}
Leukocyte rolling has been postulated to be mandatory for subsequent leukocyte adhesion and tissue injury observed during ischemia/reperfusion. The objective of this study was to systematically assess this hypothesis at the microvascular level by examining the effects of various concentrations of a selectin-binding carbohydrate (fucoidin) on the increased rolling and adhesion of leukocytes in postischemic venules. The contribution of $L$-selectin and/or P-selectin to leukocyte rolling were also assessed in this model. Using intravital microscopy we observed that $60 \mathrm{~min}$ of ischemia followed by reperfusion caused a profound increase in leukocyte rolling and adhesion. A high dose of fucoidin $(25 \mathrm{mg} / \mathrm{kg}) \mathrm{re}-$ duced leukocyte rolling by $>90 \%$ and significantly reduced leukocyte adhesion, whereas a lower dose of fucoidin still reduced leukocyte rolling by $60 \%$ but had no effect on leukocyte adhesion. Moreover, despite the profound reduction in leukocyte rolling with fucoidin, the remaining rolling cells were able to firmly adhere via a CD18-dependent mechanism, particularly in those postcapillary venules with reduced $(30-50 \%)$ shear rates. The increased rolling was also reduced $60 \%$ by either an anti-P-selectin antibody, an antiL-selectin antibody, or a combination of the two antibodies, but this reduction in rolling cells did not translate into significantly reduced leukocyte adhesion. Our data suggest that L-selectin, P-selectin, and a fucoidin-sensitive pathway contribute to the significant increase in reperfusion-induced leukocyte rolling. However, targeting leukocyte rolling as a form of therapy requires very significant efficacy ( $>90 \%$ ) to achieve reasonable $(\sim 50 \%)$ attenuation in leukocyte adhesion in postischemic venules. (J. Clin. Invest. 1995. 95:2510-2519.) Key words: L-selectin • P-selectin • adhesion - carbohydrate • fucoidin
\end{abstract}

\section{Introduction}

Infiltrating leukocytes have been implicated as key mediators of ischemia/reperfusion injury associated with the heart $(1,2)$, brain (3), intestine $(4,5)$, skeletal muscle $(6)$, and various other tissues (7-9). This contention is based primarily on three

Address correspondence to Paul Kubes, Immunology Research Group, Department of Medical Physiology, Faculty of Medicine, University of Calgary, Calgary, Alberta, T2N 4N1, Canada. Phone: 403-220-8558; FAX: 403-283-3028.

Received for publication 12 October 1994 and in revised form 18 January 1995.

J. Clin. Invest.

(C) The American Society for Clinical Investigation, Inc. $0021-9738 / 95 / 06 / 2510 / 10 \quad \$ 2.00$

Volume 95, June 1995, 2510-2519 pieces of evidence; $(a)$ leukocytes infiltrate postischemic tissue $(1,2,5),(b)$ leukocyte depletion from the circulation reduces reperfusion-induced tissue injury $(2,4)$, and $(c)$ reagents that interfere with leukocyte infiltration into postischemic vessels concomitantly provide protection against reperfusion injury ( 7 , $10-12)$. It is becoming well-recognized that leukocyte infiltration from blood to postischemic tissue is a multistep process that includes initial contact between the leukocyte and endothelium, followed by a weak transient adhesive interaction manifested as leukocyte rolling and ultimately firm leukocyte adhesion to the vessel wall $(13,14)$. Firm adhesion then allows leukocytes to transmigrate across the vessel wall to final target sites. The molecular mechanisms underlying leukocyte rolling have become the focus of much investigation, at least in part because it is felt that this process is a prerequisite for leukocyte adhesion and may therefore serve as a target for therapeutic intervention in reperfusion injury.

The selectins, a family of differentially expressed adhesive molecules which recognize fucosylated carbohydrate ligands, have been proposed to be responsible for the initial rolling observed at the onset of acute inflammation (15-18). L-selectin, found constitutively on all circulating leukocytes, has been shown to play a very important role in leukocyte rolling in flow chambers in vitro (15), and in postcapillary venules in vivo $(19,20)$. Endothelium-derived P-selectin is a second member of the selectin family that may support rapid induction of leukocyte rolling in vivo. P-selectin is rapidly translocated to the endothelial cell surface (from Weibel-Palade bodies) in response to various mediators of acute inflammation including oxidants, histamine, thrombin, and cysteinyl leukotrienes (21). The rapid mobilization of this selectin to the plasma membrane by such agents as histamine has been implicated in leukocyte rolling on endothelium initially in vitro (22) and subsequently in vivo $(23,24)$.

However, the importance of individual selectins and their ligands as they pertain to leukocyte rolling and subsequent leukocyte adhesion in postischemic tissue is not well understood. Despite the premise that leukocyte rolling is a prerequisite for leukocyte adhesion, available data suggest that antiselectin therapy is less effective than antiintegrin (antiadhesion) therapy. Functional inhibition (with monoclonal antibodies) of L-selectin or P-selectin only partially reduced $(\sim 50 \%)$ the reperfusion-induced tissue injury in the cat myocardium $(12,25)$. By contrast, P-selectin antibody did not provide any protection against reperfusion of postischemic skeletal muscle, whereas an L-selectin antibody was only moderately effective in this tissue (26). In contrast, prevention of neutrophil adhesion by immunoneutralizing $\beta_{2}$-integrin in identical postischemic models, consistently prevented reperfusion-induced tissue injury by $>85 \%$ $(1,4,26)$. Assuming that in these studies the antiselectin therapy truly did prevent leukocyte rolling, an inevitable conclusion is that intervening in the $\beta_{2}$-integrin-mediated adhesion process is generally far more effective than intervening in the selectindependent rolling event. 
A limitation of the aforementioned studies is the lack of data regarding the contribution of L-selectin and P-selectin and other adhesive mechanisms to leukocyte rolling and adhesion in the postischemic microvasculature. In this study we used intravital microscopy to visualize on-line increased leukocyte rolling, adhesion, and hemodynamic alterations in single postischemic venules and we undertook the following objectives. First, we systematically assessed the degree of leukocyte rolling and adhesion that occurs in postischemic vessels where L-selectin, P-selectin, or L-selectin + P-selectin have been immunoneutralized. Second, we determined the effects of various concentrations of the selectin-binding polysaccharide, fucoidin (a homopolymer of fucose) on leukocyte rolling and adhesion in postischemic vessels. Based on the fucoidin data, we quantified the relationship between the extent of leukocyte rolling and the degree of leukocyte adhesion during ischemia/reperfusion, i.e., how effective is the prevention of leukocyte rolling to subsequent leukocyte adhesion? Third, we examined whether other factors such as variable reductions in shear rates in postischemic vessels might not alter the relationship between the degree of leukocyte rolling and the magnitude of leukocyte adhesion.

\section{Methods}

Intravital microscopic studies. The experimental preparation used in this study is the same as that described previously (27-30). Briefly, cats $(1.2-2.4 \mathrm{~kg})$ were fasted for $24 \mathrm{~h}$ and initially anesthetized with ketamine hydrochloride ( $75 \mathrm{mg}$ intramuscularly). The jugular vein was cannulated and anesthesia was maintained by administration of pentobarbital sodium. A tracheotomy was performed to support breathing by artificial ventilation. Systemic arterial pressure was monitored by a pressure transducer (Statham P23A; Gould Inc., Oxnard, CA) connected to a catheter in the left carotid artery. A midline abdominal incision was made and a segment of small intestine was isolated from the ligament of Treitz to the ileocecal valve. The remainder of the small and large intestine was extirpated. Body temperature was maintained at $37^{\circ} \mathrm{C}$ using an infrared heat lamp. All exposed tissues were moistened with salinesoaked gauze to prevent evaporation. Heparin sodium $(10,000 \mathrm{U}$, ElkinsSinn, Inc., Cherry Hill, NJ) was administered, then an arterial circuit was established between the superior mesenteric artery (SMA) ${ }^{1}$ and left femoral artery. SMA blood flow was continuously monitored using an electromagnetic flowmeter (Carolina Medical Electronics, Inc., King, NC) and SMA pressure was measured via a T-tube interposed within the arterial circuit which was connected to a pressure transducer (Cobe Laboratories Inc., Lakewood, CO). Blood pressures and SMA blood flow were continuously recorded with a physiological recorder (Grass Instruments Co., Quincy, MA).

Cats were placed in a supine position on an adjustable plexiglass microscope stage and a segment of mid-jejunum was exteriorized through the abdominal incision. The mesentery was prepared for in vivo microscopic observation as previously described (27-30). The mesentery was draped over an optically clear viewing pedestal that allowed for transillumination of a 3-cm segment of tissue. The temperature of the pedestal was maintained at $37^{\circ} \mathrm{C}$ with a constant temperature circulator (model 80; Fisher Scientific Co., Pittsburgh, PA). The exposed bowel was draped with saline soaked gauze while the remainder of the mesentery was covered with Saran Wrap (Dow Corning Corp., Midland, MI). The exposed mesentery was suffused with warmed bicarbonate-buffered saline ( $\mathrm{pH} 7.4$ ) that was bubbled with a mixture of $5 \%$ $\mathrm{CO}_{2}$ and $95 \% \mathrm{~N}_{2}$. The mesenteric preparation was observed through an intravital microscope (Optiphot-2; Nikon Inc., Mississauga, Canada)

1. Abbreviations used in this paper: SMA, superior mesenteric artery; $\mathrm{V}_{\mathrm{RBC}}$, red blood cell velocity.
Table I. Hemodynamic State of Untreated Animals

\begin{tabular}{|c|c|c|c|c|}
\hline & \multirow[b]{2}{*}{ Control } & \multirow[b]{2}{*}{ Ischemia } & \multicolumn{2}{|c|}{ Reperfusion } \\
\hline & & & $10 \mathrm{~min}$ & $60 \mathrm{~min}$ \\
\hline $\begin{array}{l}\text { Systemic blood pressure } \\
(\mathrm{mmHg})\end{array}$ & $98 \pm 13$ & $107 \pm 18$ & $98 \pm 11$ & $92 \pm 15$ \\
\hline $\begin{array}{l}\text { Intestinal blood flow } \\
(\mathrm{ml} / \mathrm{min} \text { per } 100 \mathrm{~g})\end{array}$ & $66 \pm 8$ & $13 \pm 2 *$ & $51 \pm 8^{*}$ & $46 \pm 9 *$ \\
\hline Venular diameter $(\mu \mathrm{m})$ & $32.2 \pm 1.7$ & $33.7 \pm 1.5$ & $34.5 \pm 2.0$ & $34.0 \pm 1.9$ \\
\hline $\begin{array}{l}\text { Mean red blood cell } \\
\text { velocity }(\mathrm{mm} / \mathrm{s})\end{array}$ & $2.5 \pm 0.4$ & $0.7 \pm 0.3^{*}$ & $2.1 \pm 0.5$ & $2.1 \pm 0.7$ \\
\hline Shear rate $\left(\mathrm{s}^{-1}\right)$ & $612 \pm 93$ & $170 \pm 48^{*}$ & $470 \pm 85$ & $459 \pm 136$ \\
\hline
\end{tabular}

$* P<0.05$ relative to control value $(n=6)$.

with a $\times 25$ objective lens (Wetzlar L25/0.35; E. Leitz Inc., Munich, Germany) and a $\times 10$ eyepiece. The image of the microcirculatory bed $(\times 1,400$ magnification) was recorded using a video camera (Digital 5100; Panasonic, Osaka, Japan) and a video recorder (NV8950; Panasonic).

Single unbranched mesenteric venules (25-40- $\mu \mathrm{m}$ diameter, 250 $\mu \mathrm{m}$ length) were selected for each study. Venular diameter was measured either on- or off-line using a video caliper (Microcirculation Research Institute, Texas A \& M University, College Station, TX). The number of rolling and adherent leukocytes was determined off-line during play-back of videotaped images by two individuals. Rolling leukocytes were defined as white blood cells that moved at a velocity less than that of erythrocytes in a given vessel. The number of rolling leukocytes (flux) was counted using frame-by-frame analysis. To obtain a complete leukocyte rolling velocity profile, the rolling velocity of all leukocytes entering the vessel was measured. A leukocyte was defined as adherent to venular endothelium if it remained stationary for $>30$ s. Adherent cells were measured at 10 -min intervals as described in the experimental protocol and expressed as the number per 100- $\mu \mathrm{m}$ length of venule. Red blood cell velocity $\left(\mathrm{V}_{\mathrm{RBC}}\right)$ was measured using an optical Doppler velocimeter (Microcirculation Research Institute) and mean red blood cell velocity $\left(\mathrm{V}_{\text {mean }}\right)$ was determined as $\mathrm{V}_{\mathrm{RBC}} / 1.6$ (31). Wall shear rate was calculated based on the Newtonian definition: shear rate $=\left(V_{\text {mean }} / D_{v}\right) \times 8\left(s^{-1}\right)$, where $D_{v}$ is the venular diameter.

\section{Experimental protocol}

In vivo experiments. After a 1-h stabilization period, baseline measurements of blood pressure, SMA blood flow, and $\mathrm{V}_{\mathrm{RBC}}$ were obtained. In the first group of animals $(n=6)$, the preparation was videotaped for $10 \mathrm{~min}$ and then SMA blood flow was mechanically reduced (Gaskell clamp) to $20 \%$ of control for $1 \mathrm{~h}$. The last $10 \mathrm{~min}$ of the ischemic period were videotaped and then the clamp was removed to restore intestinal blood flow. The first $10 \mathrm{~min}$ and last $10 \mathrm{~min}$ of the $60-\mathrm{min}$ reperfusion period were also videotaped. In a second series of animals $(n=5)$, an identical protocol was completed, however the animals received mAb DREG 200 (L-selectin-blocking IgG1-clone; $1 \mathrm{mg} / \mathrm{kg}$ ) before the onset of reperfusion. Using standard flow cytometric techniques we demonstrated that DREG 200 antibody cross-reacts with cat leukocytes (described later in Methods). This concentration of DREG 200 has been shown to $(a)$ maximally inhibit leukocyte interactions with excised cat coronary vessels and $(b)$ attenuate reperfusion injury to the myocardium (12). Since the L-selectin antibody did not completely prevent reperfusion-induced leukocyte rolling, in a third group of animals both DREG 200 and mAb PB1.3 (P-selectin-blocking IgG1-clone $352 ; 2 \mathrm{mg} / \mathrm{kg}$; Cytel Corp., San Diego, CA) were given before reperfusion. This concentration of P-selectin antibody has previously been used in pretreatment regimens to maximally prevent tissue injury in feline myocardium (25) and to prevent leukocyte rolling in the cat microvasculature (32). Moreover, it has been demonstrated that PB1.3 stains cat 

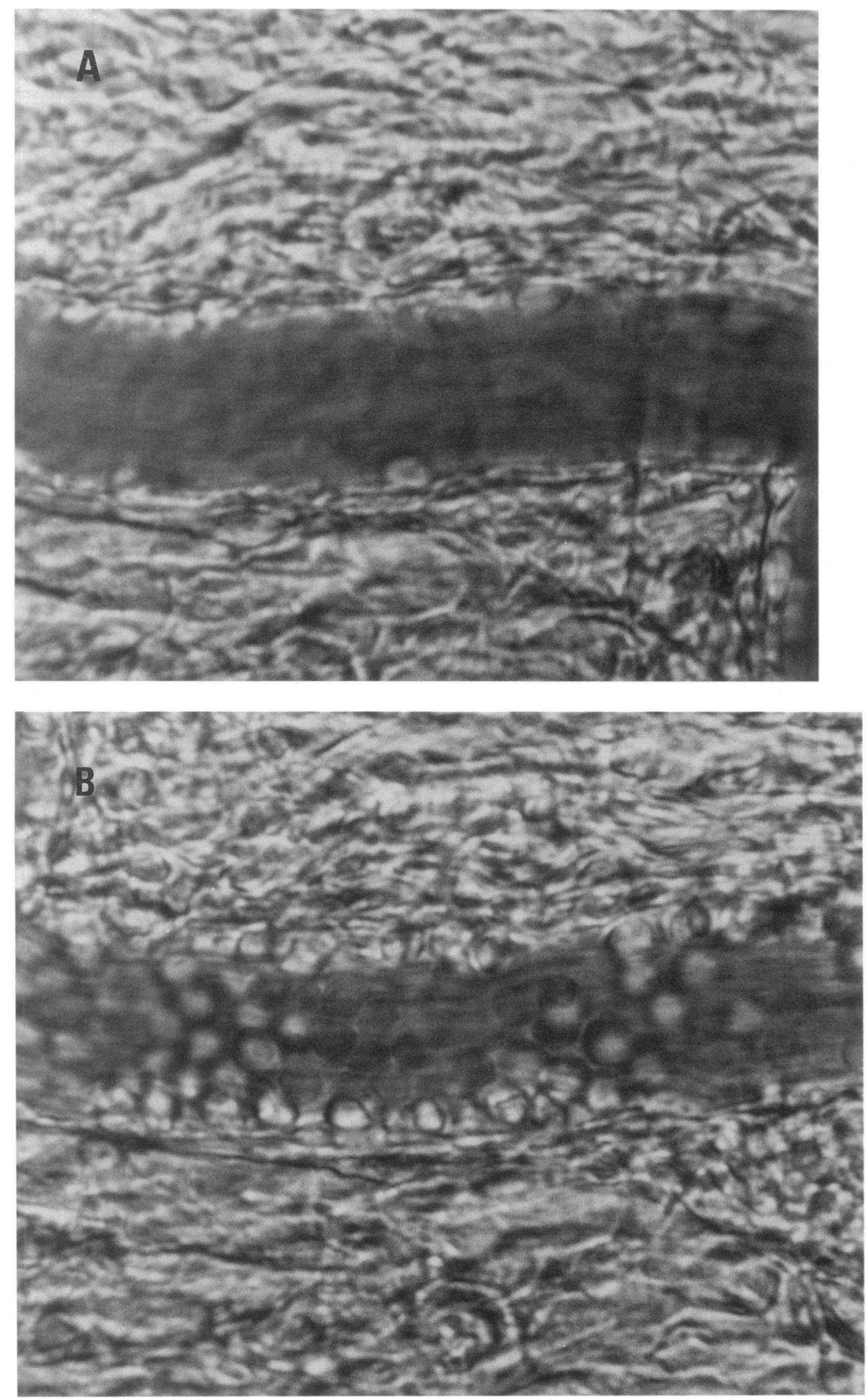

Figure 1. Photomicrographs of a $38-\mu \mathrm{m}$ venule under $(A)$ control conditions, $(B) 2$ min reperfusion, $(C) 4 \mathrm{~min}$ reperfusion, and $(D) 10 \mathrm{~min}$ reperfusion. Three leukocytes can be seen rolling through the venule under control conditions increasing to $\sim 100$ cells rolling or adhering in the venule at 4 min of reperfusion. Playback analysis (frame by frame) is necessary to quantitate rolling and adherent leukocytes. Not shown is the fact that this leukocytic influx is restricted to venules (not arterioles). endothelium and prevents thrombin-induced leukocyte binding to excised postischemic coronary vessels (25). For completeness, in a third group of animals, the P-selectin antibody was given alone as previously described (11). Finally, a nonspecific mouse IgG antibody was used as a negative control. This antibody did not affect reperfusion-induced leukocyte rolling or adhesion, so these animals were grouped with the untreated animals.

In the next series of experiments, the selectin-binding polysaccharide, fucoidin (Sigma Chemical Co., St. Louis, MO), a homopolymer of sulfated L-fucose, was administered to animals at two different concentrations ( 1 or $25 \mathrm{mg} / \mathrm{kg}$ ), $5 \mathrm{~min}$ before reperfusion. Additionally, in some animals, fucoidin $(25 \mathrm{mg} / \mathrm{kg})$ was administered after $60 \mathrm{~min}$ of reperfusion when leukocyte rolling and firm adhesion were already present to determine whether fucoidin could reverse these reperfusioninduced events. Finally, despite a profound reduction in leukocyte rolling with fucoidin $(25 \mathrm{mg} / \mathrm{kg})$, some adhesion persisted. To ensure that the adhesion was CD18-dependent, some animals received fucoidin (25 $\mathrm{mg} / \mathrm{kg})$ and $\mathrm{mAb} \mathrm{IB}_{4}(1 \mathrm{mg} / \mathrm{kg})$ the anti-CD18 antibody. This concentration of $\mathrm{mAb} \mathrm{IB}_{4}$ has previously been reported to completely prevent reperfusion-induced neutrophil adhesion in the cat (30).

In vitro adherence assay. The assumption that fucoidin directly interferes with leukocyte rolling but not firm adhesion, was confirmed 

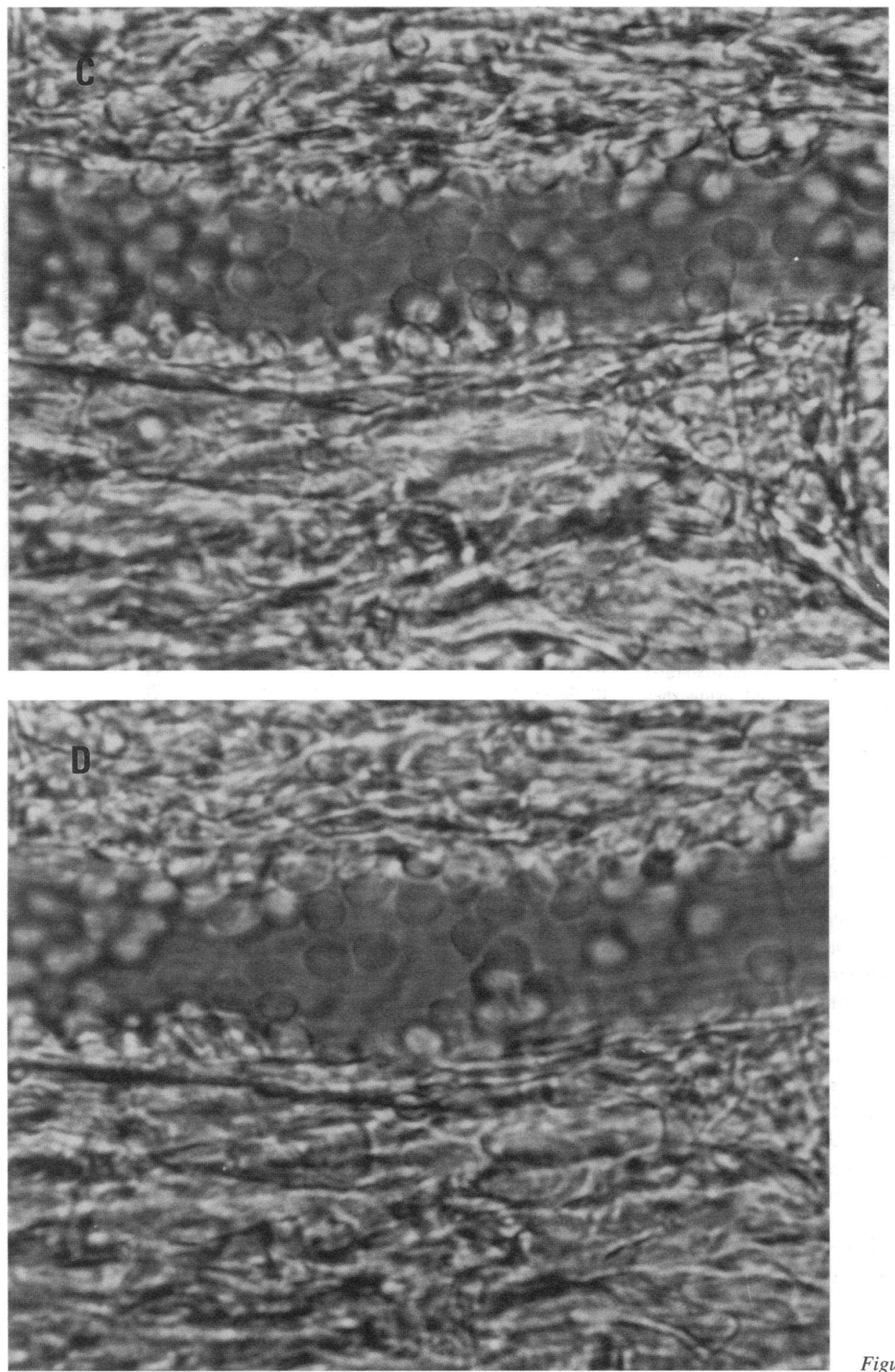

Figure 1 (Continued)

by examining feline leukocyte adhesion in a static adhesion assay system in vitro. Feline neutrophils were purified using a one-step dextran sedimentation followed by hypotonic lysis and histopaque centrifugation as previously described (28). After isolation, neutrophils were resuspended at a final concentration of $2 \times 10^{7}$ cells $/ \mathrm{ml}$ in PBS. The leukocyte adhesion assay was a modification of the method of Fehr and Dahinden (33). Briefly, leukocytes were radiolabeled by incubating purified feline neutrophils $\left(2 \times 10^{7}\right.$ cell $\left./ \mathrm{ml}\right)$ with $30 \mu \mathrm{Ci} / \mathrm{ml}$ of $\mathrm{Na}^{51} \mathrm{CrO}_{4}$ at $37^{\circ} \mathrm{C}$ for $60 \mathrm{~min}$. The cells were washed three times and resuspended in PBS. Neutrophils were allowed to adhere to FCS-coated plastic for $30 \mathrm{~min}$ in the presence of PMA $\left(3 \times 10^{-7} \mathrm{M}\right)$ a stimulus of CD18-dependent neutrophil adhesion. In other wells, the neutrophils were stimulated with PMA in the presence of either the monoclonal antibody directed against $\mathrm{CD} 18\left(\mathrm{IB}_{4}\right)$, or various concentrations of fucoidin.

Flow cytometric analysis was performed to confirm that DREG 200 was binding to L-selectin on feline neutrophils. Briefly, whole heparinized blood was collected into sterile 5-ml vacutainer tubes. The anticoagulated blood was transferred into polypropylene tubes $(90 \mu \mathrm{l})$ and $10 \mu \mathrm{l}$ of either DREG 200 (final concentration $10 \mu \mathrm{g} / \mathrm{ml}$ ) or saline were added to the whole blood aliquots for $10 \mathrm{~min}$ at $37^{\circ} \mathrm{C}$, and then centrifuged for $30 \mathrm{~s}$ in a microcentrifuge $(10,000 \mathrm{~g})$. The cells were washed and exposed to a goat anti-mouse IgG labeled with FITC conju- 
Table II. Leukocyte Kinematics of Untreated Animals

\begin{tabular}{lllll}
\hline & & \multicolumn{2}{c}{ Reperfusion } \\
\cline { 5 - 5 } \cline { 4 - 5 } & Control & Ischemia & 10 min & 60 min \\
\hline $\begin{array}{c}\text { Leukocyte rolling flux } \\
\quad(\text { cells/min) }\end{array}$ & $55 \pm 17$ & $23 \pm 9$ & $178 \pm 59 *$ & $152 \pm 46^{*}$ \\
$\begin{array}{c}\text { Leukocyte rolling velocity } \\
(\mu \mathrm{m} / \mathrm{s})\end{array}$ & $81 \pm 19$ & $10 \pm 4^{*}$ & $38 \pm 5^{*}$ & $82 \pm 24$ \\
$\begin{array}{c}\text { Leukocyte adhesion } \\
(\text { cells } / 100-\mu \mathrm{m} \text { venule) }\end{array}$ & $4.1 \pm 1.4$ & $14.2 \pm 1.9 *$ & $18.3 \pm 4.1^{*}$ & $20.2 \pm 4.7^{*}$
\end{tabular}

${ }^{*} P<0.05$ relative to control value $(n=6)$.

gate as secondary antibody. The red cells were then lysed using a whole blood lysing reagent kit. The leukocytes were washed and binding of DREG 200 to feline neutrophils was measured the same day on a FACScan $^{\bullet}$ (Becton Dickinson Immunocytometry Systems, Mountain View, CA). Data are consistent with previous work (12); the mean channel fluorescence value was 7.1 and 292.8 for the control and DREG 200 antibody, respectively, and $99.9 \%$ of neutrophils stained positively with DREG 200.

Statistics. Statistical analyses were performed by conventional methods; all time points within a group were subjected to Friedmann's nonparametric test and data between groups were compared using the Mann-Whitney $U$ test. All values in the text and figures are expressed as means $\pm \mathrm{SE}$ and statistical significance is set at $P<0.05$.

\section{Results}

Ischemia/reperfusion-induced hemodynamic parameters. Table I summarizes the hemodynamic data from six untreated animals exposed to ischemia $(1 \mathrm{~h})$ and reperfusion $(1 \mathrm{~h})$. Systemic blood pressure remained unchanged throughout the experiment suggesting that reperfusion of the small bowel was not inducing systemic blood pressure effects. Intestinal blood flow was $\sim 66 \mathrm{ml} / \mathrm{min}$ per $100 \mathrm{~g}$ under normal conditions. The $1 \mathrm{~h}$ of reduced blood flow (ischemia) was always followed by a rapid transient hyperemic blood flow response (first few minutes of reperfusion). Intestinal blood flow then decreased significantly with time of reperfusion to 77 and $70 \%$ of control at 10 and $60 \mathrm{~min}$, respectively. This translated into a significant reperfusion-induced increase in vascular resistance in this organ (data not shown). At the level of the venule, venular diameter, shear rates, and mean $\mathrm{V}_{\mathrm{RBC}}$ did not change significantly with ischemia/reperfusion. In the six experimental groups, none of the hemodynamic parameters were significantly different from the untreated group and therefore are not presented herein.

Ischemia/reperfusion-induced leukocyte kinetics. Fig. 1 is a series of photomicrographs depicting leukocyte influx into a single $38-\mu \mathrm{m}$ venule of an untreated animal under control conditions and immediately after reperfusion. It is clear that within the first 2-10 min of reperfusion a very rapid increase in leukocyte infiltration can be observed. Table II summarizes the data of leukocyte behavior after $1 \mathrm{~h}$ of ischemia and $1 \mathrm{~h}$ of reperfusion. Under control conditions, 50-60 leukocytes/min roll past a given point consistent with the view that background leukocyte rolling exists in postcapillary venules in surgically exposed vessels of the $\operatorname{dog}(34)$, rat (35), mouse (36), hamster (37), rabbit (13), in undisturbed vessels of the hamster skin (38), and the ear of the hairless mouse (39). The rolling veloc-

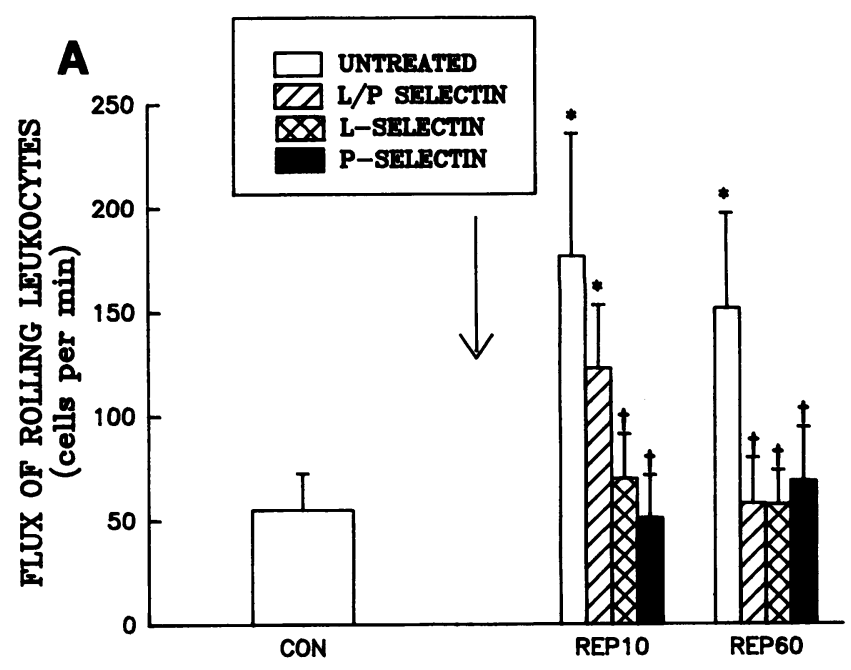

B

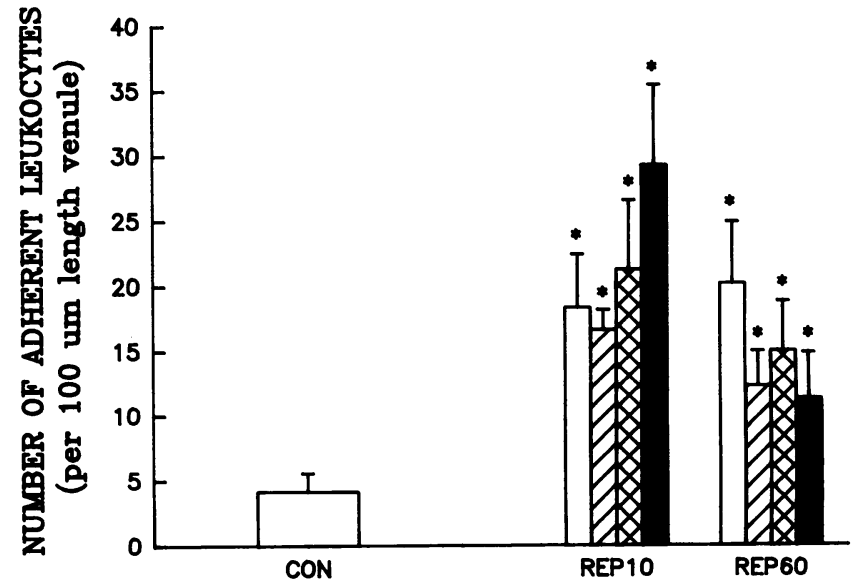

Figure 2. Leukocyte $(A)$ rolling flux and $(B)$ adhesion during control $(C O N)$ and at 10 and 60 min of reperfusion $(R E P)$ in untreated animals and animals pretreated with either the anti-L-selectin (DREG 200), anti-P-selectin (PB1.3) antibody, or both ( $n=20$, total). The antibodies were administered at $55 \mathrm{~min}$ of ischemia and the intestine was reperfused at 60 min. ${ }^{*} P<0.05$ relative to control. ${ }^{\dagger} P<0.05$ relative to untreated group.

ity of these cells varied dramatically from as slow as a few micrometers per second to $\sim 300 \mu \mathrm{m} / \mathrm{s}$. There were very few adherent leukocytes under control conditions in these animals. During ischemia when hemodynamic dispersal forces were very low, and rouleaux formation was evident, leukocytes accumulated within the postcapillary venules. When blood flow was reintroduced to the mesentery, the accumulated leukocytes were flushed out of the vessel so that very few of the adhering cells remain immediately after the onset of reperfusion. Within the next 1-3 min a very profound increase in the number of rolling leukocytes was observed that reached peak levels (as high as 400 cells $/ \mathrm{min}$ in one animal) within the first $5 \mathrm{~min}$. Leukocyte rolling was maintained at elevated levels for the duration of the experiment. The rolling velocity of leukocytes during the first $10 \mathrm{~min}$ of reperfusion was always much slower than that observed either during control conditions or by $60 \mathrm{~min}$ of reperfusion; an effect mediated at least in part by platelet-activating 


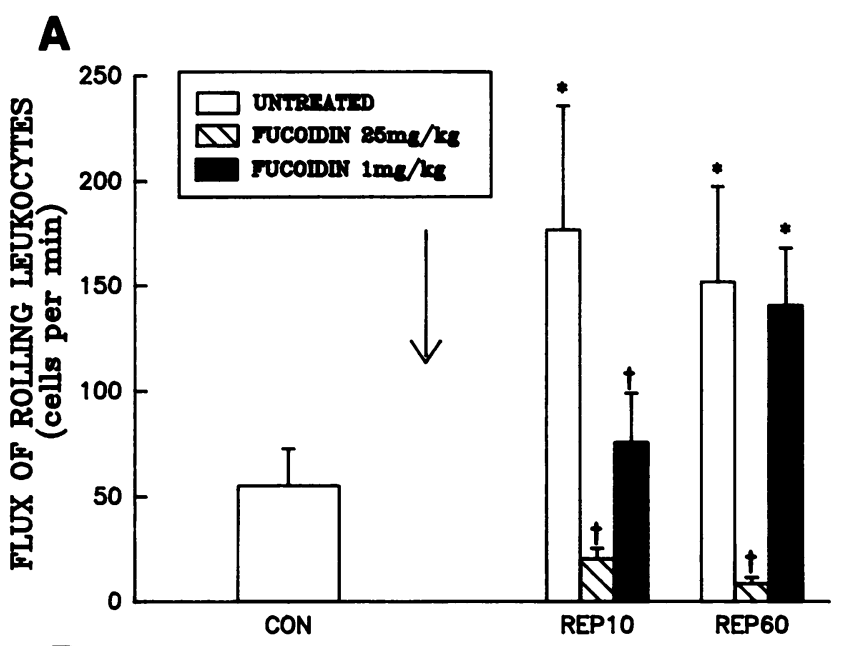

B

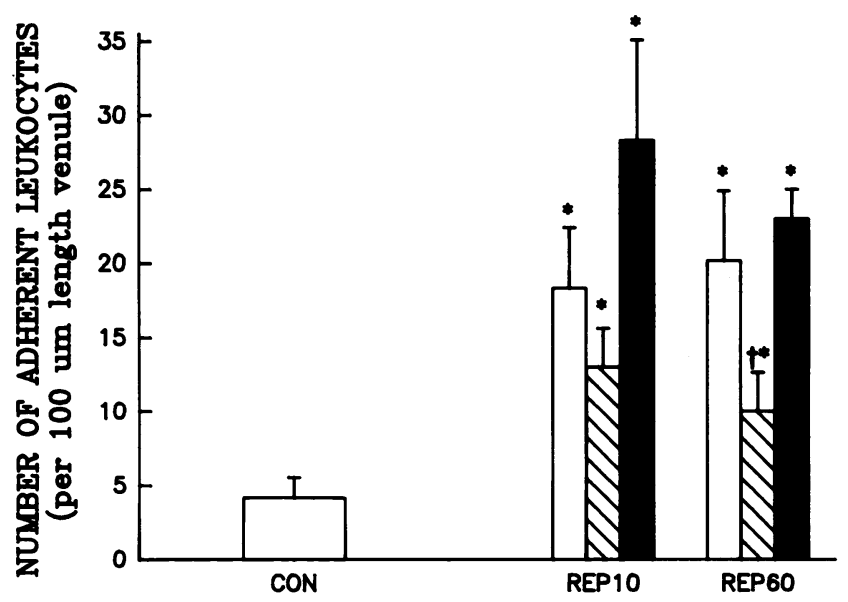

Figure 3. Leukocyte $(A)$ rolling flux and $(B)$ adhesion during control $(C O N)$ and at 10 and 60 min of reperfusion $(R E P)$ in untreated animals and animals pretreated with fucoidin at 1 and $25 \mathrm{mg} / \mathrm{kg}$ before reperfusion ( $55 \mathrm{~min}$ ischemia). Fucoidin ( $1 \mathrm{mg}$ ) was used because it temporarily reduced leukocyte rolling to the level of the antibodies and allowed for direct comparison of adhesion between groups (Fig. 2). The leukocyte rolling however returned to control levels by $60 \mathrm{~min}(n=16$, total). ${ }^{*} P<0.05$ relative to control. ${ }^{\dagger} P<0.05$ relative to untreated group.

factor (40). Leukocyte adhesion increased significantly by 10 and $60 \mathrm{~min}$ of reperfusion (Table II).

Role of L-selectin and P-selectin in ischemia/reperfusion. Fig. 2 summarizes the data for leukocyte rolling and adhesion in untreated animals and animals given anti-L-selectin antibody (DREG 200) before reperfusion. $A$ illustrates that the number of rolling leukocytes was decreased by $\sim 60 \%$ at both 10 and $60 \mathrm{~min}$ of reperfusion. This significant reduction in leukocyte rolling did not prevent or even attenuate leukocyte adhesion (Fig. 2, B). Fig. 2 also summarizes the data for leukocyte rolling and adhesion in animals given both anti-L-selectin and anti-Pselectin antibody or anti-P-selectin antibody alone just before reperfusion. Administration of P-selectin antibody alone also significantly reduced leukocyte rolling by $\sim 60 \%$. Dual antiL-selectin and anti-P-selectin therapy followed a similar pattern as L-selectin therapy administration, i.e., 60\% inhibition in leukocyte flux at $60 \mathrm{~min}$. At $10 \mathrm{~min}$, one of the animals did not
Table III. Effect of Fucoidin Posttreatment on Leukocyte Rolling Flux and Adhesion During Reperfusion

\begin{tabular}{lcc}
\hline & \multicolumn{2}{c}{ Fucoidin } \\
\cline { 2 - 3 } & Before & After \\
\hline Leukocyte rolling flux (cells/min) & $141 \pm 55$ & $11 \pm 4^{*}$ \\
Leukocyte adhesion per $100-\mu \mathrm{m}$ length venule & $30.3 \pm 6.6$ & $26.3 \pm 6.7$
\end{tabular}

Fucoidin $(25 \mathrm{mg} / \mathrm{kg})$ was administered at $60 \mathrm{~min}$ of reperfusion and the vessel was observed for the next $10 \mathrm{~min}$. ${ }^{*} P<0.05$ relative to before value $(n=3)$.

respond to L- and P-selectin immunoneutralization, explaining the relatively high number of rolling cells at this time point. In all three groups, a $60 \%$ reduction in leukocyte rolling flux failed to have a significant effect on leukocyte adhesion. The possibility always exists that the use of these intact IgG antibodies may have a direct proadhesive effect on leukocytes in vivo, explaining the selective reduction in leukocyte rolling but not adhesion with DREG 200 and PB1.3. It should, however, be noted that these antibodies did not augment feline neutrophil adhesion to protein-coated plastic or human umbilical vein endothelial cells in the presence or absence of PMA, and these antibodies did not cause $\mathrm{Ca}^{2+}$ influx into feline neutrophils in vitro (data not shown).

Role of a selectin-binding carbohydrate (fucoidin) in ischemia/reperfusion. Since there was a significant proportion of rolling leukocytes after L- and P-selectin antibody administration, in another series, we tested the selectin-binding polysaccharide, fucoidin, to determine whether the residual population of rolling leukocytes could be ablated with this homopolymer of sulfated fucose, and if so than to determine whether this complete reduction in rolling translated into a reduction in adhesion. Fig. 3 demonstrates that fucoidin $(25 \mathrm{mg} / \mathrm{kg})$ essentially abolished $(>90 \%)$ leukocyte rolling in vivo and significantly reduced leukocyte adhesion. The reduction in leukocyte adhesion was likely a result of the reduction in leukocyte rolling because administration of fucoidin $25 \mathrm{mg} / \mathrm{kg}$ after $60 \mathrm{~min}$ of reperfusion completely inhibited leukocyte rolling, but had little or no effect on leukocyte adhesion (Table III). Also illustrated in Fig. 3 is the fact that the lower concentration of fucoidin ( 1 $\mathrm{mg} / \mathrm{kg}$ ) reduced leukocyte rolling by $60 \%$ (much like the antiL- and/or anti-P-selectin therapy) and under these conditions leukocyte adhesion was not significantly different from the untreated control. By $60 \mathrm{~min}$, leukocyte rolling had returned to control levels at the low concentration of fucoidin (Fig. 3).

Despite essentially complete inhibition of leukocyte rolling with fucoidin, significant leukocyte adhesion was still evident (particularly at $10 \mathrm{~min}$ of reperfusion). Therefore, we examined minute by minute the number of rolling cells over the first 10 min reperfusion period, to ensure that fucoidin did indeed prevent the initial leukocyte rolling influx. Table IV summarizes that the rapid rise in leukocyte rolling was initiated within the first 2 min of reperfusion and was maintained throughout the $10 \mathrm{~min}$ (as well as $60 \mathrm{~min}$ ) of reperfusion. Fucoidin essentially abolished this leukocytic influx throughout the entire $60 \mathrm{~min}$ of reperfusion.

Further assessment of the data revealed two populations of animals in the fucoidin group, i.e., those in which shear rates decreased substantially during reperfusion $(<70 \%$ of control 
Table IV. Effect of Fucoidin on Leukocyte Rolling Flux during First 10 Min of Reperfusion

\begin{tabular}{lcccccccccc}
\hline & \multicolumn{10}{c}{ Reperfusion } \\
\cline { 2 - 9 } & $1 \mathrm{~min}$ & $2 \mathrm{~min}$ & $3 \mathrm{~min}$ & $4 \mathrm{~min}$ & $5 \min$ & $6 \min$ & $7 \min$ & $8 \mathrm{~min}$ & $9 \mathrm{~min}$ & $10 \mathrm{~min}$ \\
\hline $\begin{array}{l}\text { Untreated } \\
\text { Fucoidin } \\
(25 \mathrm{mg} / \mathrm{kg})\end{array}$ & $130 \pm 31$ & $211 \pm 98$ & $212 \pm 80$ & $211 \pm 69$ & $187 \pm 47$ & $190 \pm 44$ & $181 \pm 49$ & $156 \pm 36$ & $149 \pm 31$ & $178 \pm 59$ \\
\hline
\end{tabular}

${ }^{*} P<0.05$ relative to untreated value. Fucoidin was given just before reperfusion (control $n=6$; fucoidin $n=6$ ), values in cells $/ \mathrm{min}$.

value, group 1) and another population of animals in which the vessel under observation reperfused back to controls $(>70 \%$ of control values, group 2 ). The $70 \%$ value was chosen arbitrarily to divide the two groups into low and high shear vessels. When we examined the degree of adhesion in these two populations (Fig. 4) a striking difference was observed. Leukocyte adhesion was not significantly decreased in the low shear rate

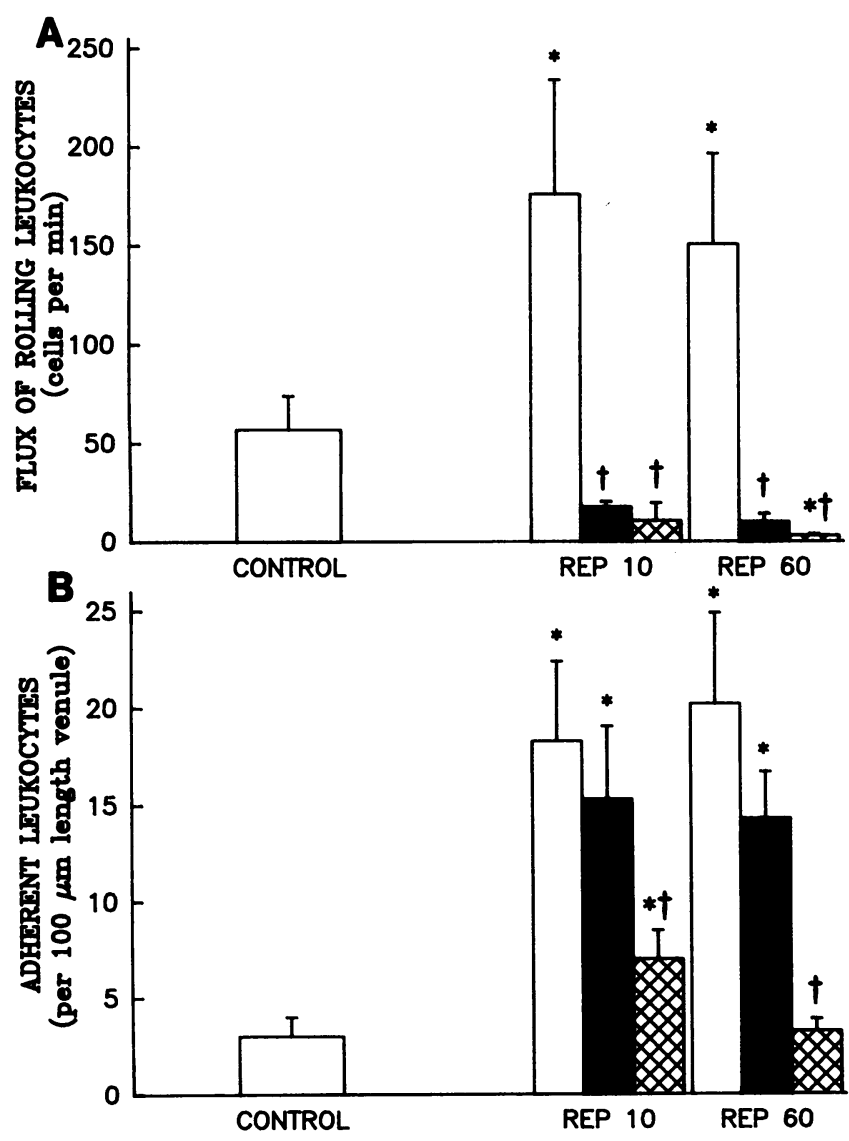

Figure 4. Leukocyte $(A)$ rolling flux and $(B)$ adhesion during control $(C O N)$ and at 10 and 60 min of reperfusion $(R E P)$ in untreated and fucoidin-treated animals $(25 \mathrm{mg} / \mathrm{kg})$ in which, after a brisk hyperemia, either a $30 \%$ or greater reduction in venular red blood cell velocity was observed (group 1) or after hyperemia, venular red blood cell velocity was maintained above or near control levels (group 2). The $70 \%$ of control value was chosen arbitrarily to divide the fucoidin animals into two groups $\left(n=12\right.$, total). ${ }^{*} P<0.05$ relative to control. ${ }^{\dagger} P<0.05$ relative to untreated group. ( $\square$ ) Untreated. ( $\square$ ) Fucoidin group 1: $<70 \%$ of preischemic value. ( Fucoidin group $2:>70 \%$ of preischemic value. vessels, whereas leukocyte adhesion was essentially abolished in those vessels that reperfused back to control levels (Fig. 4). Since in all cases leukocyte rolling was reduced during reperfusion by $\sim 90 \%$ with fucoidin, it appears that the few rolling leukocytes adhere far more effectively in vessels with reperfusion-induced reduction in shear rates than in those with higher shear rates. To ensure that this shear rate-dependent leukocyte adhesion was mediated by the $\beta_{2}$-integrin, in another group, animals received $\mathrm{mAb} \mathrm{IB}_{4}$ along with fucoidin. Under low shear rate conditions when fucoidin was not effective at preventing leukocyte adhesion, anti- $\beta_{2}$-integrin therapy entirely abolished reperfusion-induced leukocyte adhesion (Fig. 5).

To confirm that fucoidin did not directly inhibit leukocyte adhesion, we performed in vitro experiments. PMA-induced feline leukocyte adhesion to protein-coated substratum was entirely abolished by CD18 antibody but was unaffected by fucoidin (Table V).

\section{Discussion}

The two-step model of leukocyte infiltration into tissues defines a role for selectins and their carbohydrate ligands in the initial leukocyte rolling event and a role for the integrins and their counterpart ligands including intracellular adhesion molecule1 and other molecules in the adhesion process $(13,14)$. More-

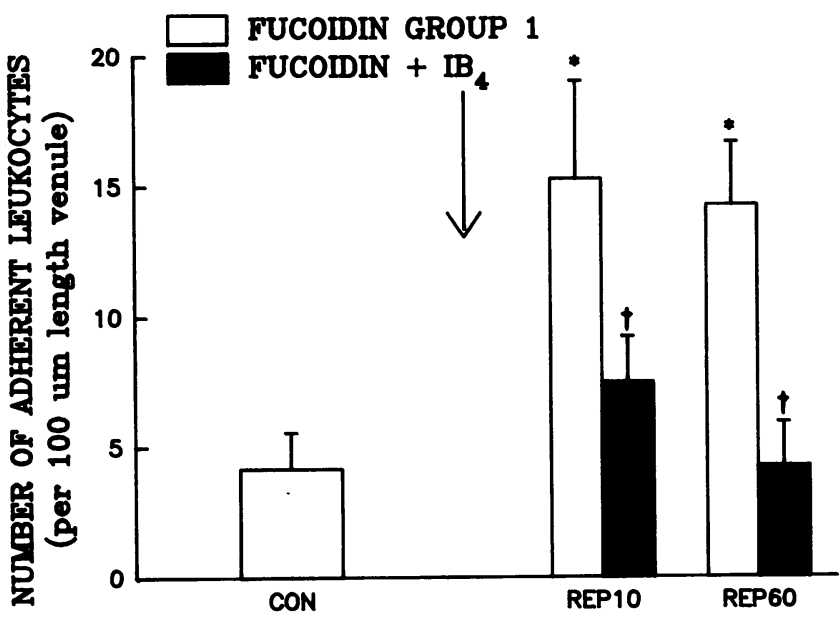

Figure 5. Leukocyte adhesion in postischemic animals treated with fucoidin $(25 \mathrm{mg} / \mathrm{kg}$, group 1 , see Fig. 4 legend $)$ or fucoidin + the anti$\mathrm{CD} 18$ antibody $\mathrm{IB}_{4}$. In all these vessels studied the red blood cell velocity was $<70 \%$ of control (CON) during the reperfusion (REP) phase $(n=7$, total $) .{ }^{*} P<0.05$ relative to control. ${ }^{\dagger} P<0.05$ relative to untreated value. 
over, since this is an interdependent cascade of events, i.e., a leukocyte cannot adhere unless it initially makes contact with and rolls along the endothelium, presumably there should be a positive correlation between the degree of leukocyte rolling and the degree of leukocyte adhesion. By inference, antitherapeutic agents that reduce leukocyte rolling should therefore also decrease the amount of leukocyte adhesion and leukocyte infiltration into tissues. With respect to these views, we present herein, that although leukocyte rolling is an important prerequisite for adhesion, the relationship is not linear in nature. Our data suggest that at the onset of an inflammatory condition such as reperfusion of ischemic tissue there is a superfluous amount of rolling leukocytes $(\sim 150-200$ cells $/ \mathrm{min})$ and only a small proportion of these cells adhere $(\sim 20$ cells $/ 100 \mu \mathrm{m}$ length venule [10 min measurement]), perhaps due to a limited number of adhesion sites. In fact, $<1 \%$ of rolling leukocytes adhered to postischemic venules in this study, a value previously reported by others in postcapillary venules at normal and low shear rate conditions (41). Because of this surplus or reserve of rolling leukocytes, it is conceivable that the reduction in leukocyte rolling has to reach a critical level to impact on leukocyte adhesion.

Support for this contention is the observation herein that reducing leukocyte rolling by $60 \%$ with fucoidin $(1 \mathrm{mg} / \mathrm{kg})$, a sulfated homopolymer of fucose, did not reduce the leukocyte adhesion in postischemic venules (Fig. 3). Clearly, the remaining rolling cells were sufficient in number to maintain the same degree of leukocyte adhesion as was observed in untreated animals. However, when a very significant reduction in leukocyte rolling ( $90 \%)$ was achieved with a higher concentration of fucoidin $(25 \mathrm{mg} / \mathrm{kg})$, the normal reperfusion-induced leukocyte adhesion was attenuated by $50 \%$. These data would indeed support the view that targeting leukocyte rolling as a form of therapy requires very high efficacy to achieve a significant attenuation in leukocyte adhesion. Moreover, even when leukocyte rolling was reduced by $90 \%$ with fucoidin, a significant proportion of leukocytes adhered in venules if shear rates were $<70 \%$ of control (Fig. 4). Clearly, the efficiency of leukocyte adhesion during low rolling states was significantly improved when shear rates were compromised by as little as $30 \%$. This is likely an important factor to consider in light of the fact that in various forms of inflammation, vessels dilate and hydrodynamic dispersal forces are often reduced by $50 \%(17,42,43)$. The leukocyte adhesion during lower hydrodynamic dispersal forces was not simply a "stopping phenomenon"' as a result of insufficient shear, but rather a CD18-dependent leukocyte adhesion inasmuch as an antibody directed against the $\beta_{2}$-integrin prevented the leukocyte adhesion. Although the reason for the reduced blood flow response in some but not all vessels during reperfusion remains unclear, this observation underscores the complexity of the in vivo situation during inflammation and the potential complications associated with designing therapeutic agents to inhibit leukocyte infiltration.

Another issue addressed by this study was the importance of L- and P-selectin in leukocyte rolling during ischemia/reperfusion. The two antibodies reduced the magnitude of reperfusion-induced leukocyte rolling to very similar degrees $(60 \%)$ suggesting a significant contribution of these adhesion molecules to leukocyte rolling in postischemic vessels in vivo. To determine whether L- and P-selectin might mediate leukocyte rolling by two independent rolling pathways, L- and P-selectin antibodies were coadministered in some preparations. If indeed
Table V. Fucoidin Does Not Inhibit Neutrophil Adhesion In Vitro

\begin{tabular}{lc}
\hline \multicolumn{1}{c}{ Condition } & Adhesion to HUVEC \\
\hline & $\%$ \\
Control & $10.8 \pm 1.6$ \\
PMA $(200 \mathrm{ng} / \mathrm{ml})$ & $44.2 \pm 8.3^{*}$ \\
PMA + fucoidin $(0.1 \mathrm{mg} / \mathrm{ml})$ & $52.8 \pm 3.3^{*}$ \\
PMA + fucoidin $(1.0 \mathrm{mg} / \mathrm{ml})$ & $55.5 \pm 5.3^{*}$ \\
PMA + IB $(20 \mu \mathrm{g} / \mathrm{ml})$ & $6.5 \pm 1.2^{\ddagger}$ \\
\end{tabular}

${ }^{*} P<0.05$ relative to control. ${ }^{\ddagger} P<0.05$ relative to PMA. $n=$ run in triplicate. HUVEC, human umbilical vein endothelial cells.

two separate pathways exist, then tandem immunoneutralization of P- and L-selectin would provide an additive inhibition of reperfusion-induced leukocyte rolling. The fact that dual immunoneutralization did not provide any additional reduction in reperfusion-associated leukocyte rolling relative to either P-selectin or L-selectin antibody alone, supports previous in vitro work suggesting that leukocytic L-selectin and endothelial Pselectin are reciprocal receptor ligands. Picker et al. have proposed that L-selectin interacts with $\mathrm{P}$-selectin since leukocyte binding to P-selectin transfectants was inhibited by an anti-Lselectin antibody (44). Others have, however, questioned the importance of a P-selectin/L-selectin interaction inasmuch as soluble P-selectin binding to leukocytes remains intact when Lselectin is shed from the surface (reviewed in reference 18).

An alternative explanation for the lack of additive effect of coadministration of the two antiselectin antibodies may be related to the fact that the two selectins mediate different components of leukocyte rolling in a sequential manner so that one is dependent on the other. Leukocyte rolling may consist of two distinct events, a first step, the initial attachment (tethering, catching) of leukocytes to the endothelial cell, and a second step, the actual rolling event along the endothelium. In support of this view, Lawrence et al. (45) demonstrated that L-selectin expression was essential for tethering of leukocytes to surfaces coated with purified E-selectin, whereas L-selectin-independent ligands on the leukocyte (after L-selectin was shed), may mediate the subsequent rolling event. Whether P-selectin serves the role of a ligand for tethering, rolling, or both, remains to be determined.

It is noteworthy that despite a reduction in leukocyte rolling ( $60 \%)$ by immunoneutralization of P-selectin, L-selectin, or both rolling pathways with antibodies, leukocyte adhesion was not attenuated. These data are consistent with the observation that fucoidin at the low dose $(1 \mathrm{mg} / \mathrm{kg})$ caused only a $60 \%$ reduction in leukocyte rolling and therefore also failed to reduce leukocyte adhesion. However the antibody data should be interpreted with caution inasmuch as intravital microscopy does not allow for discrimination between cell types. Therefore, if the rolling leukocytes are a nonhomogenous population of cells, the possibility always exists that the antibodies inhibit a population of rolling cells that were not destined to adhere firmly to the postischemic venules. Until a selective intravital stain is available for different cell types (neutrophils, eosinophils, monocytes, and lymphocytes), great caution must be taken when assessing leukocyte rolling in vivo not to treat the rolling leukocytes as a single homogenous population of cells interacting with the endothelium via the same adhesive molecules. 
The observation herein that L-selectin and P-selectin antibodies did not attenuate the leukocyte adhesion in postischemic mesenteric vessels is consistent with findings that anti-P-selectin antibody did not reduce postischemic skeletal muscle injury and that L-selectin only reduced injury to a relatively small degree (26). On the other hand, a relatively large reduction in reperfusion injury with $\mathrm{P}$ - and L-selectin antibodies has been reported in the feline heart $(12,25)$ and rabbit ear (7). It is possible that unlike in cat mesenteric postischemic vessels, in postischemic heart and ear vessels, P-selectin and L-selectin antibodies are far more effective at reducing leukocyte rolling. Alternatively, it is possible that antiselectin antibodies affect other leukocyte rolling-independent mechanisms. Indeed, in a recent study, leukocytic influx and tissue protection did not coincide; P-selectin antibody protected the lung from distant reperfusion injury without reducing leukocyte infiltration (46). Whether this is related to inhibitory effects of anti-P-selectin antibody on, for example, activated platelets or activated endothelium remains to be elucidated. Clearly these potential complications underscore the importance of carefully assessing the effects of selectin antibodies on leukocyte behavior in vessels in various postischemic organs in vivo.

The data herein consistently revealed a third rolling pathway independent of P-selectin or L-selectin, but inhibitable by fucoidin. This sulfated homopolymer of fucose did not lower the circulating leukocyte count in this study or the number of freeflowing cells through microvessels in other studies $(47,48)$, making leukocytopenia an unlikely explanation for the very profound reduction in leukocyte rolling. Since fucoidin binds to and avidly inhibits both L-selectin and P-selectin interactions, one possible explanation for the greater effectiveness of fucoidin than antiselectin antibody therapy is another adhesive mechanism inhibitable by the carbohydrate polymer. An obvious candidate to explain the L- and P-selectin-independent leukocyte rolling is E-selectin, the third member of the selectin family and a glycoprotein also postulated to induce leukocyte rolling (49). It is, however, unlikely that E-selectin participates in this rolling event since the leukocyte rolling in this study was abolished by fucoidin yet fucoidin has been shown not to bind to E-selectin $(18,50)$. Although the identity of the fucoidin-sensitive pathway remains unknown, it is conceivable that fucoidin, a heavily sulfated polysaccharide, may interfere with the ability of leukocytes to interact with sulfate-containing proteoglycans on the surface of vascular endothelium. Although this hypothesis is presently purely speculative, various other sulfated molecules have been shown to strongly interfere with leukocyte rolling in vivo (51-53) and leukocyte adhesion in vitro (54). Finally, the possibility exists that fucoidin is a more effective inhibitor of selectin function than the monoclonal antibodies, which may be only partially effective as blocking antibodies against feline selectins.

In conclusion our data suggest that reperfusion of postischemic vessels induces a rise in leukocyte rolling that is dependent on L-selectin, P-selectin, and a third adhesive mechanism that is fucoidin sensitive. Although leukocyte rolling is indeed associated with leukocyte adhesion, the two events are not entirely interdependent, inasmuch as only a relatively small proportion of rolling leukocytes is required to obtain a normal reperfusioninduced leukocyte adhesion response. Finally, from a therapeutic viewpoint, the ability to reduce leukocyte adhesion by reducing leukocyte rolling may be greatly improved if the hydrodynamic dispersal forces are not compromised during the onset of reperfusion and carbohydrate moieties such as fucoidin, which block multiple rolling pathways are used.

\section{Acknowledgments}

This work was supported by a grant from the Alberta Heritage Foundation for Medical Research, the Canadian Medical Research Council, and the Canadian Heart and Stroke Foundation.

\section{References}

1. Ma, X.-L., P. S. Tsao, and A. M. Lefer. 1991. Antibody to CD-18 exerts endothelial and cardiac protective effects in myocardial ischemia and reperfusion. J. Clin. Invest. 88:1237-1243.

2. Romson, J. L., B. G. Hook, S. L. Kunkel, G. D. Abrams, A. Schork, and B. R. Lucchesi. 1983. Reduction in the extent of ischemic myocardial injury by neutrophil depletion in the dog. Circulation. 67:1016-1023.

3. Mori, E., G. J. del Zoppo, J. D. Chambers, B. R. Copeland, and K. E. Arfors. 1992. Inhibition of polymorphonuclear leukocyte adherence suppresses no-reflow after focal cerebral ischemia in baboons. Stroke. 23:712-718.

4. Hernandez, L. A., M. B. Grisham, B. Twohig, K. E. Arfors, J. M. Harlan, and D. N. Granger. 1987. Role of neutrophils in ischemia-reperfusion-induced microvascular injury. Am. J. Physiol. 253:H699-H703.

5. Granger, D. N. 1988. Role of xanthine oxidase and granulocytes in ischemiareperfusion injury. Am. J. Physiol. 255:H1269-H1275.

6. Korthuis, R. J., M. B. Grisham, and D. N. Granger. 1988. Leukocyte depletion attenuates vascular injury in postischemic skeletal muscle. Am. J. Physiol. 254:H823-H827.

7. Winn, R. K., D. Liggitt, N. B. Vedder, J. C. Paulson, and J. M. Harlan. 1993. Anti-P-selectin monoclonal antibody attenuates reperfusion injury to the rabbit ear. J. Clin. Invest. 92:2042-2047.

8. Jaeschke, H., A. Farhood, and C. W. Smith. 1990. Neutrophils contribute to ischemia/reperfusion injury in rat liver in vivo. FASEB (Fed. Am. Soc. Exp. Biol.) J. 4:3355-3359.

9. Welbourn, C. R. B., G. Goldman, I. S. Paterson, C. R. Valeri, D. Shepro, and H. B. Hechtman. 1991. Neutrophil elastase and oxygen radicals: synergism in lung injury after hindlimb ischemia. Am. J. Physiol. 260:H1852-H1856.

10. Grisham, M. B., L. A. Hernandez, and D. N. Granger. 1989. Adenosine inhibits ischemia-reperfusion-induced leukocyte adherence and extravasation. Am. J. Physiol. 257:H1334-H1339.

11. Kubes, P., I. Kurose, and D. N. Granger. 1994. NO donors prevent integrininduced leukocyte adhesion, but not P-selectin-dependent rolling in postischemic venules. Am. J. Physiol. 267:H931-H937.

12. Ma, X.-L., A. S. Weyrich, D. J. Lefer, M. Buerke, K. H. Albertine, T. K. Kishimoto, and A. M. Lefer. 1993. Monoclonal antibody to L-selectin attenuates neutrophil accumulation and protects ischemic reperfused cat myocardium. Circulation. 88:649-658.

13. Von Andrian, U. H., J. D. Chambers, L. M. McEvoy, R. F. Bargatze, K. E. Arfors, and E. C. Butcher. 1991. Two-step model of leukocyte-endothelial cell interaction in inflammation: distinct roles for LECAM-1 and the leukocyte $\beta_{2}$ integrins in vivo. Proc. Natl. Acad. Sci. USA. 88:7538-7542.

14. Springer, T. A. 1990. Adhesion receptors of the immune system. Nature (Lond.). 346:425-434.

15. Smith, C. W., T. K. Kishimoto, O. Abbass, B. Hughes, R. Rothlein L. V. McIntire, E. Butcher, and D. C. Anderson. 1991. Chemotactic factors regulate lectin adhesion molecule 1 (LECAM-1)-dependent neutrophil adhesion to cytokine-stimulated endothelial cells in vitro. J. Clin. Invest. 87:609-618.

16. Zimmerman, G. A., S. M. Prescott, and T. M. McIntyre. 1992. Endothelial cell interactions with granulocytes: tethering and signaling molecules. Immunol. Today. 13:93-99.

17. Lawrence, M. B., and T. A. Springer. 1991. Leukocytes roll on a selectin at physiologic flow rates: distinction from and prerequisite for adhesion through integrins. Cell. 65:859-873.

18. Bevilacqua, M. P., and R. M. Nelson. 1993. Selectins. J. Clin. Invest. 91:379-387.

19. Ley, K., P. Gaehtgens, C. Fennie, M. S. Singer, L. A. Lasky, and S. D. Rosen. 1991. Lectin-like cell adhesion molecule 1 mediates leukocyte rolling in mesenteric venules in vivo. Blood. 77:2553-2555.

20. Von Andrian, U. H., P. Hansell, J. D. Chambers, E. M. Berger, I. T. Filho, E. C. Butcher, and K. E. Arfors. 1992. L-selectin function is required for $\beta_{2-}$ integrin-mediated neutrophil adhesion at physiological shear rates in vivo. Am. J. Physiol. 263:H1034-H1044.

21. Geng, J.-G., M. P. Bevilacqua, K. L. Moore, T. M. McIntyre, S. M Prescott, J. M. Kim, G. A. Bliss, G. A. Zimmerman, and R. P. McEver. 1990 Rapid neutrophil adhesion to activated endothelium mediated by GMP-140. $\mathrm{Na}$ ture (Lond.). 343:757-760.

22. Jones, D. A., O. Abbassi, L. V. McIntire, R. P. McEver, and C. W. Smith 
1993. P-selectin mediates neutrophil rolling on histamine-stimulated endothelial cells. Biophys. J. 65:1560-1569.

23. Kubes, P., and S. Kanwar. 1994. Histamine induces leukocyte rolling in post-capillary venules: a P-selectin-mediated event. J. Immunol. 152:3570-3577.

24. Asako, H., I. Kurose, R. Wolf, S. DeFrees, Z.-L. Zheng, M. L. Phillips, J. C. Paulson, and D. N. Granger. 1994. Role of $\mathrm{H1}$ receptors and P-selectin in histamine-induced leukocyte rolling and adhesion in postcapillary venules. $J$. Clin. Invest. 93:1508-1515.

25. Weyrich, A. S., X.-L. Ma, D. J. Lefer, K. H. Albertine, and A. M. Lefer. 1993. In vivo neutralization of P-selectin protects feline heart and endothelium in myocardial ischemia and reperfusion injury. J. Clin. Invest. 91:2620-2629.

26. Seekamp, A., G. O. Till, M. S. Mulligan, J. C. Paulson, D. C. Anderson, M. Miyasaka, and P. A. Ward. 1994. Role of selectins in local and remote tissue injury following ischemia and reperfusion. Am. J. Pathol. 144:592-598.

27. Kubes, P., M. B. Grisham, J. A. Barrowman, T. Gaginella, and D. N. Granger. 1991. Leukocyte-induced vascular protein leakage in cat mesentery. Am. J. Physiol. 261:H1872-H1879.

28. Kubes, P., M. Suzuki, and D. N. Granger. 1991. Nitric oxide: an endogenous modulator of leukocyte adhesion. Proc. Natl. Acad. Sci. USA. 88:46514655 .

29. Kanwar, S., and P. Kubes. 1994. Ischemia/reperfusion-induced granulocyte influx is a multistep process mediated by mast cells. Microcirc. 1:175-182.

30. Granger, D. N., J. N. Benoit, M. Suzuki, and M. B. Grisham. 1989. Leukocyte adherence to venular endothelium during ischemia-reperfusion. Am. J. Physiol. 257:G683-G688.

31. House, S. D., and H. H. Lipowsky. 1987. Leukocyte-endothelium adhesion: microhemodynamics in mesentery of the cat. Microvasc. Res. 34:363-379.

32. Bienvenu, K., and D. N. Granger. 1993. Molecular determinants of shear rate-dependent leukocyte adhesion in postcapillary venules. Am. J. Physiol. 264:H1504-H1587.

33. Fehr, J., and C. Dahinden. 1979. Modulating influence of chemotactic factor-induced cell adhesiveness on granulocyte function. J. Clin. Invest. 64:816.

34. Dore, M., R. J. Korthuis, D. N. Granger, M. L. Entman, and C. W. Smith. 1993. P-selectin mediates spontaneous leukocyte rolling in vivo. Blood. 82:13081316.

35. Gaboury, J., D. C. Anderson, and P. Kubes. 1994. Molecular mechanisms involved in superoxide-induced leukocyte-endothelial cell interactions in vivo. Am. J. Physiol. 266:H637-H642.

36. Mayadas, T. N., R. C. Johnson, H. Rayburn, R. O. Hynes, and D. D. Wagner. 1993. Leukocyte rolling and extravasation are severely compromised in P-selectin-deficient mice. Cell. 74:541-554.

37. Del Maestro, R. F., M. Planker, and K. E. Arfors. 1982. Evidence for the participation of superoxide anion radical in altering the adhesive interaction between granulocytes and endothelium, in vivo. Int. J. Microcirc. Clin. Exp. 1:105120.

38. Lehr, H. A., E. Kress, M. D. Menger, H. P. Friedl, C. Hubner, K. E.
Arfors, and K. Messmer. 1993. Cigarette smoke elicits leukocyte adhesion to endothelium in hamsters: inhibition by CuZn-SOD. Free Radic. Biol. \& Med. 14:573-581.

39. Mayrovitz, H. N. 1992. Leukocyte rolling: a prominent feature of venules in intact skin of anaesthetized hairless mice. Am. J. Physiol. 262:H157-H161.

40. Kubes, P., G. Ibbotson, J. M. Russell, J. L. Wallace, and D. N. Granger. 1990. Role of platelet-activating factor in ischemia/reperfusion-induced leukocyte adherence. Am. J. Physiol. 259:G300-G305.

41. Bienvenu, K., J. Russell, and D. N. Granger. 1993. Platelet-activating factor promotes shear rate-dependent leukocyte adhesion in postcapillary venules. J. Lipid Mediators. 8:95-103.

42. Engler, R. L., G. W. Schmid-Schonbein, and R. S. Pavelec. 1983. Leukocyte capillary plugging in myocardial ischemia and reperfusion in the dog. Am. J. Pathol. 111:98-111.

43. Mori, E., G. J. del Zoppo, J. D. Chambers, B. R. Copeland, and K. E. Arfors. 1992. Inhibition of polymorphonuclear leukocyte adherence suppresses no-reflow after focal cerebral ischemia in baboons. Stroke. 23:711-718.

44. Picker, L. J., R. A. Warnock, A. R. Burns, C. M. Doerschuk, E. L. Berg, and E. C. Butcher. 1991. The neutrophil selectin LECAM-1 presents carbohydrate ligands to the vascular selectins ELAM-1 and GMP-140. Cell. 66:921-933.

45. Lawrence, M. B., D. F. Bainton, and T. A. Springer. 1994. Neutrophil tethering to and rolling on E-selectin are separable by requirement for L-selectin. Immunity. 1:137-145.

46. Carden, D. L., J. A. Young, and D. N. Granger. 1993. Pulmonary microvascular injury after intestinal ischemia-reperfusion: role of P-selectin. J. Appl. Physiol. 75:2529-2534.

47. Ley, K., G. Linnermann, M. Meinen, L. M. Stoolman, and P. Gaehtgens. 1993. Fucoidin, but not yeast polyphosphomannan PPME, inhibits leukocyte rolling in venules of the rat mesentery. Blood. 81:177-185.

48. Lindbom, L., X. Xie, J. Raud, and P. Hedqvist. 1992. Chemoattractantinduced firm adhesion of leukocytes to vascular endothelium in vivo is critically dependent on initial leukocyte rolling. Acta Physiol. Scand. 146:415-421.

49. Lawrence, M. B., and T. A. Springer. 1993. Neutrophils roll on E-selectin. J. Immunol. 151:6338-6346.

50. Nelson, R. M., S. Dolich, A. Aruffo, O. Cecconi, and M. P. Bevilacqua. 1993. Higher-affinity oligosaccharide ligands for E-selectin. J. Clin. Invest. 91:1157-1166.

51. Arfors, K. E., and K. Ley. 1993. Sulfated polysaccharides in inflammation. J. Lab. Clin. Med. 121:201-202.

52. Ley, K., M. Cerrito, and K. E. Arfors. 1991. Sulfated polysaccharides inhibit leukocyte rolling in rabbit mesentery venules. Am. J. Physiol. 260:H1667H1673.

53. Tangelder, G. J., and K. E. Arfors. 1991. Inhibition of leukocyte rolling in venules by protamin and sulfated polysaccharides. Blood. 77:1565-1571.

54. Cecconi, O., R. M. Nelson, W. G. Roberts, K. Hanasaki, G. Mannori, C. Schultz, T. R. Ulich, A. Aruffo, and M. P. Bevilacqua. 1994. Inositol polyanions: noncarbohydrate inhibitors of L-selectin and P-selectin that block inflammation. J. Biol. Chem. 269:15060-15066. 